\title{
Causes and Countermeasures of Unemployment Rate in the Middle and Later Period of Epidemic
}

\begin{abstract}
Yifei Chen ${ }^{* 1}$
${ }^{1}$ Beijing Huiwen Middle School

*Corresponding author. Email: Chenyifei727@hotmail.com

ABSTRACT

The emergence of COVID-19 at the end of 2019 will undoubtedly have a huge impact on the world economy. The epidemic situation that has not been controlled for more than one and a half years will continue to affect the normal return to work and rehabilitation of the people. In this paper, theoretical analysis and empirical analysis will be used to analyze the situation and causes of the economy and unemployment rate in the middle and later stages of the epidemic, and make a brief prediction of the future form. This paper finds that, at present, although the economy and unemployment rate have picked up, it is still not optimistic. Countries should respond to the new round of crisis according to the world and national conditions.
\end{abstract}

Keywords: COVID-19; Economic policy; Economic recession, Unemployment rate

\section{INTRODUCTION}

Under the global economic recession triggered by the epidemic, all countries haven't been spared, with different degrees of economic regression. It can even be said that this is the most serious one in decades. As an external problem, the epidemic not only threatens life safety but also makes individuals, companies, and countries face economic problems. The unemployment rate continued to rise in just a few months. China's unemployment rate is gradually approaching its peak in 2009. On the whole, the epidemic not only brought heavy damage to the family income but also prevented the economy from functioning normally after several months of shutdown. At this time, the world has gone through the rush at the beginning of the epidemic to study how to further restore the normal operation of the economy. This paper will use the historical data of economic stagflation as a model to analyze how the world economy recovers its upward trend. At the same time, it will predict the trend of the unemployment rate in the future.

\section{THEORETICAL RELATIONSHIP BETWEEN ECONOMIC STATUS AND UNEMPLOYMENT RATE}

When a country's finance continues to shrink in two quarters, economists define it as an economic recession.
The continuous economic recession will also cause inflation, credit crunch, and less investment as well as other consequences. The rise of unemployment rate is an important and unique persistent problem of economic recession. The economic recession after the epidemic is often caused by the short-term and high-efficiency of the epidemic, that is, in the short term, the COVID-19 impacts on a large number of people, enterprises, society and the country.

Generally speaking, when consumer's confidence in buying is high and a large number of products are purchased, the market demand for products increases, and factory production either remains stable or continues to rise. In contrast, in an economic recession, consumers lose their confidence and are no longer spending as usual. In capitalist countries, the economic basis is private ownership of production, which leads to the increasing exploitation of employees by enterprises in order to expand the original accumulation of capital. When the labor force is exploited, due to the low salary flowing to their own hands, they will not have too much assets left each month. In the short-term and strong impact of the epidemic, workers' assets are scarce, which makes it impossible for them to buy a large number of goods to stimulate consumption. Due to the stagnation of production and sale, the market demand for products is greatly reduced, which has a serious impact on various industries in the short term. The serious debt has eliminated the enthusiasm for 
enterprises to continue maintaining and producing, then the most common way for enterprises to deal with the reduction of market demand is to reduce staff's wages, lay off employees, and cut the budget in the next few years. There are also some enterprises that are directly declared bankrupt because they are overburdened with debt. Every time there is an economic recession, the most damaged field's staff do not have the professional skills in other industries, finding a new job in a short time to earn their living seems like a difficulty. Without the help of governments, the public of unemployment can only wait for the industry to recover before re interviewing. At the same time, even if the economy has recovered from the recession, the unemployment rate will continue to rise for a period of time.

\section{THE ECONOMIC SITUATION AND UNEMPLOYMENT RATE OF SEVERAL COUNTRIES}

This paper by selecting several countries under the different systems to summarize and analyze the economy and unemployment rate affected by the epidemic.

\subsection{CPI(Consumer Price Index) that Continues to Fluctuate}

First of all, from the CPI data, it can be concluded that the CPI data of the United States keeps increasing from January 2019 to January 2020, with a small drop to about 262.5\% in April 2020; the CPI index of China basically maintains at about $105 \%-106 \%$ from April 2020 to the end of 2021; the CPI index of the European Union keeps rising from April 2019 to February 2020, from $107.8 \%$ to $113.7 \%$, Since then, it has remained stable until January 2021, when there was a big drop in April 2021.

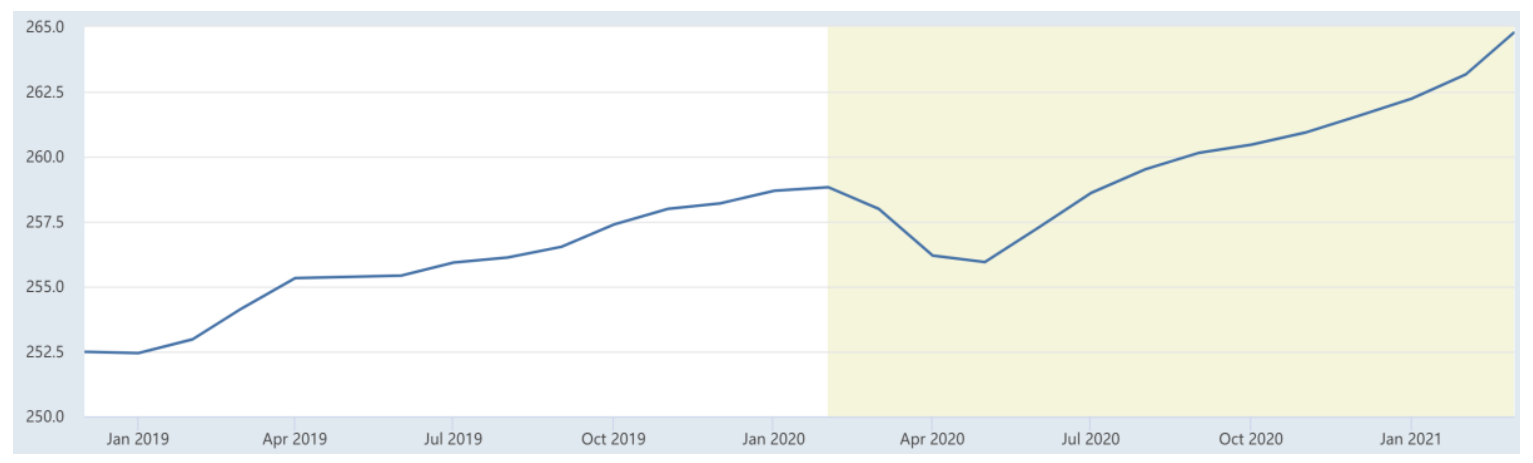

Figure 1 US consumer price index[1]

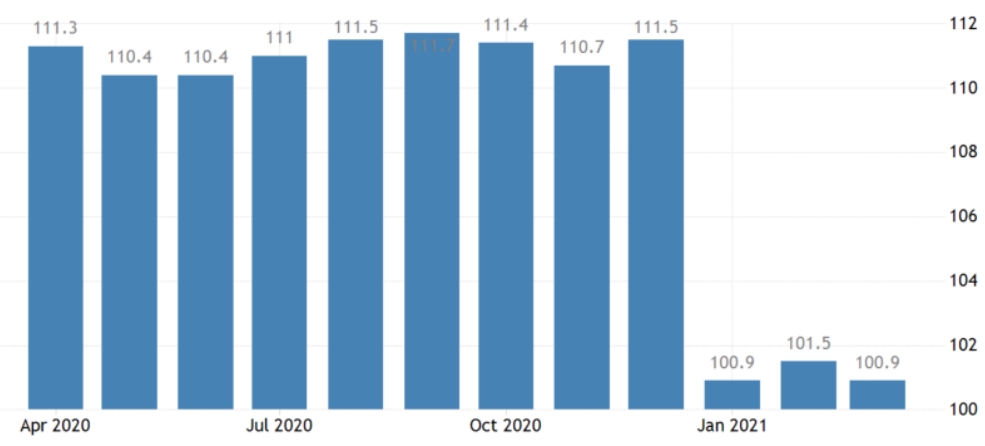

Figure 2 Consumer Price Index CPI in China[2] 


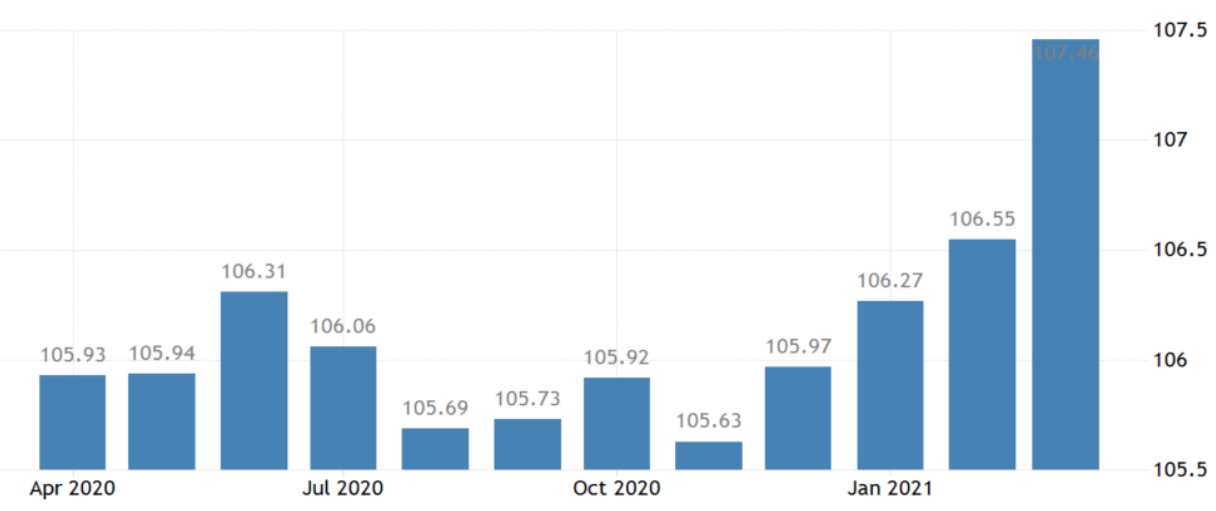

\subsection{The Rising and Unpredictable Unemployment}

According to the unemployment rate data of various countries, the unemployment rate in the United States has risen from about $3.5 \%$ before the epidemic to its peak in April 2020, about 15\%. Since then, the unemployment rate has dropped sharply, but it has not yet returned to the pre epidemic level. China's unemployment rate rose from $3.610 \%$ in December 2019 to $4.240 \%$ in December 2020. The EU's unemployment rate has risen to $7.8 \%$ in November 2020 from $6.4 \%$ in march 2019, and it fell to $7.5 \%$ after 2021 .

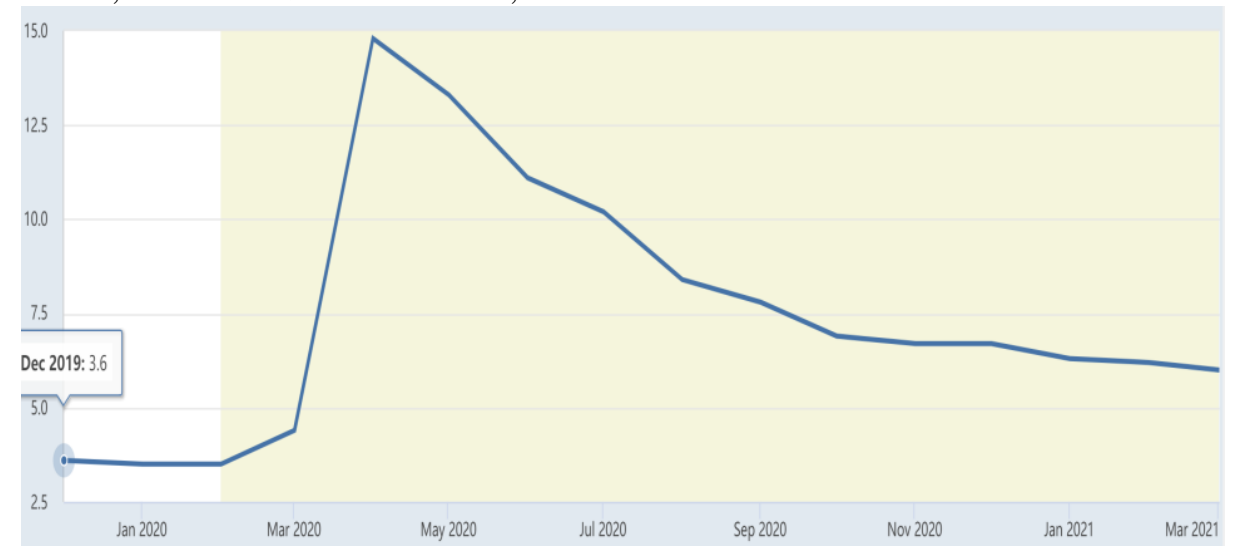

Figure 4 America unemployment rate[4]

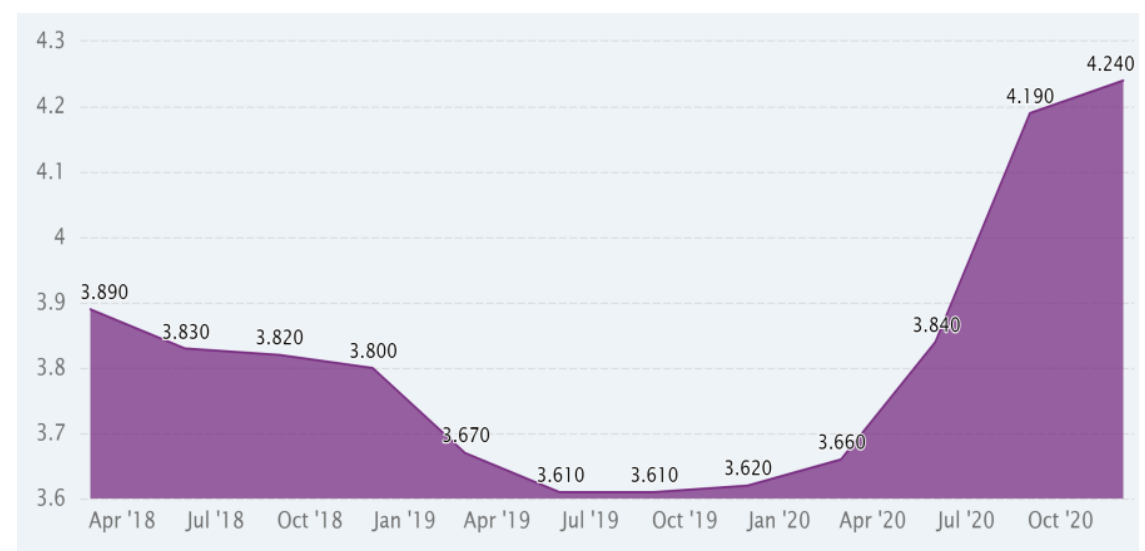

Figure 5 China Urban Survey Unemployment Rate[5] 


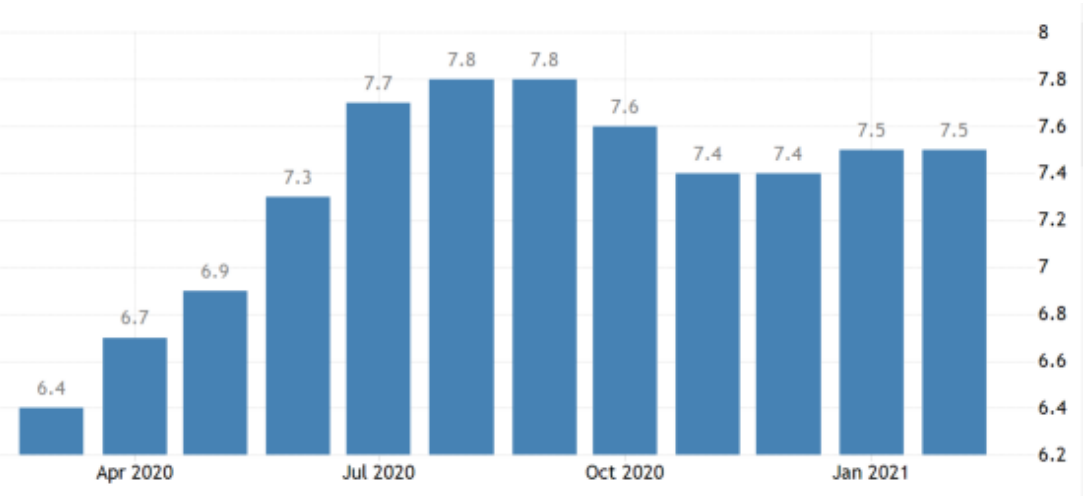

Figure 6 European Union Long Term Unemployment Rate[6]

\section{THE REASONS FOR ECONOMIC RECESSION AND CURRENT POLICIES OF COUNTRIES}

According to the data proposes by various countries, the annual economic contraction caused by COVID-19 has been approaching the financial crisis in 2008, and there hasn't existed a large economic recession in decades like what COCID-19 brings. It forms a great threat to the safety of people's life and property, and the enterprise country needs a long time adjusting to recover.Interest rates are at historical lows, and the current crisis is also generating spillover effects throughout supply chains. [7]

\subsection{Capitalist Countries}

Factors that promote the increase of unemployment rate and the instability of national foundation

\subsubsection{New liberalism leads to the difficulty of market regulation and the gap between the rich and the poor increases}

But Neoliberalism will also increase the gap between the rich and the poor. When the market and price are made by wealthy capitalists, Neoliberalism will safeguard the interests of the rich, but the poor are often the non-discourse parties.[8] The expansion of the gap between the rich and the poor began in the 1980s. In the 1980 s, the average growth rate of the first $20 \%$ of the residents' income divided by income level in the United States and that of other $80 \%$ groups has been significantly differentiated. We can see Table 1 data, in the short months after the outbreak, the United States' richest five people's property accounts for the overall proportion of people is rising. Other people are taking up a lower proportion in this statistic. The disadvantages of new liberalism also show that the government is free to let the market flow, not to carry out macro-control and intervention in prices, which ultimately leads to the expansion of market spontaneity, blindness, lag.
Although capitalist countries develop in multi-directional finance, so as to make full use of surplus-value to prevent the occurrence of excess production. Nevertheless, when the market regulation fails, governments must intervene in controlling prices because the market couldn't regulate itself at the macro-level that the whole market is unable to get adequate data in all aspects. As an administrative organ, the government has the power and obligation to gather all kinds of product Party information, making more accurate adjustments to the market. Stiglitz, a famous American economist, once wrote a critical theory" the end of history" that at the end of new liberalism and the revival of history. He has counted several major crimes of Neoliberalism: the erosion of democracy, wealth gathering and social differentiation, deregulation of financial market and financial risk, climate crisis, etc. He believes that the unrestricted market cannot work and the crisis is more aware that new liberalism will indeed end civilization. The only way forward and the only way to save our planet and civilization is the rebirth of history, and the freedom, respect for knowledge, and democratic equivalence of the enlightenment are worth extending again.

\subsubsection{Widens the gap between the rich and the poor is industrialization and financialization.}

Capitalism abandoned industry before the financial crisis of 2008 and then turned to the research and development of high-tech products and the development of the financial market. The capitalist countries in Europe and America have all located their factories in Asia because there are large and cheap labor forces, which can effectively reduce the cost of capitalist production and help them accumulate more funds. But it also creates the emptiness of capitalist countries in the real industry and the unemployment of most handicraft workers. It can be said that cheap labor in Asia has replaced the workers in western. Until the financial crisis, Obama proposed a bill to restore the real economy, the manufacturing promotion act, to restore 
the manufacturing industry that the United States has been shelved for many years, due to the recession and the sharp decline in employment. During the financial crisis, a large number of people have dismissed by companies because of the collapse of corporate debts. The unemployment rate in the United States was once as high as $10 \%$. In COVID-19, the unemployment rate reached the highest $--15 \%$ since 1950. The unemployment rate in the UK rose to 4.8 percent in the third quarter,[9]0.7 percent higher than the second quarter, 0.9 percent higher than the same period last year. Unemployment in Italy increased from 9.9 percent in 2019 to 11.1 percent in 2020 [10]. Capitalist production mode is the way of capitalist exploitation of workers. Therefore, realizing the finance, will inevitably increase the exploitation of workers and develop the commodity economy, expand the demand of the people for finance and commodities, and better accumulate capital[11]. This also leads to the widening gap between the rich and the poor in society and the unfair distribution of social means of production. The frequent financial crisis in contemporary market economies proves that the bubble and bubble burst of financial virtual assets transaction is an objective necessity which is not transferred by people's will[12]. Industrialization and finance make capitalism develop more and more to the opposite side of the real economy, and the whole country tends to be more and more virtual.

The malpractice that capitalism can effectively develop science and technology, new liberalism and industrialization, and finance is also reflected in this COVID-19. Because the government is minimized by neoliberalism and almost all enterprises are privatized, the government cannot effectively allocate medical devices and other necessities in time when a public health crisis occurs. Deindustrialization and finance lead to the economic bubble of the state, without the support of the real economy, and the prosperity of the economy is always unstable. More importantly, the lack of a real economy will expand the gap between the rich and the poor, reduce employment and make the life of the people at the bottom of society extremely unstable

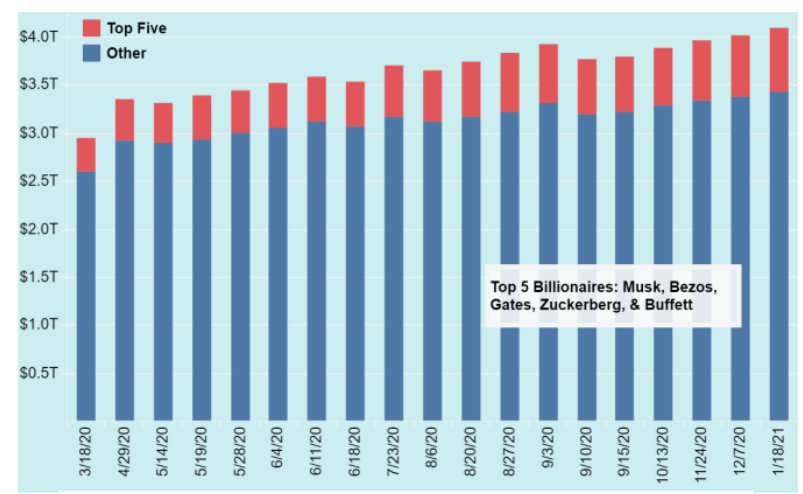

Figure 7 The gap between the rich and the poor[13]

\subsection{Socialist Countries}

In this epidemic, socialist countries as a whole were slightly affected, showing a trend of good development. Socialism originated from utopian socialism in England. It advocates that society should be the main body of society, and society should own and control products, capital, land, and assets. Its management and distribution are based on public interests, and its economic basis is public ownership of means of production. Compared with western capitalism, the public ownership of means of production to a large extent eliminates the dominance of private enterprises. In the event of a major public health crisis, the main goal for socialist countries is to protect people's health. Instead, the capitalist countries only act for the sake of interests and greatly encourages enterprises and employees to return to work and production before the epidemic is being controlled. Nonetheless, socialist countries promote the integration of administrative parties, which can quickly respond to the public health crisis and uniformly allocate medical materials. Since all socialist countries are governed by one party, we can avoid fighting among various parties and concentrate consideration on the public during the epidemic period.

\subsubsection{The government issued effective prevention and control policies}

In the early days of the outbreak in China, the national government responded quickly, ordering Wuhan to be closed down, while a large number of medical staff rushed to Wuhan. In China, we have also established a refined epidemic prevention and control system, which has been deployed from the provincial, municipal, town, and township levels, establishing an effective social support system.

Other socialist countries, such as Cuba and North Korea, have issued strong policies such as border blockade to prevent the spread of the epidemic in their own countries. Even if Cuba's epidemic rebounded in March 2021, the president immediately ordered the closure of the city, again ordered the closure of restaurants, bars and swimming pools, suspended public transport, and banned people from entering the beach [14]

\subsubsection{People's attention to the epidemic situation and freedom of publicity}

The people in socialist countries have more collective consciousness and emphasize collective education rather than individual freedom. Under the threat of the epidemic, the whole people can lay down their own interests temporarily and facilitate the implementation of policies. 
Therefore, although socialist countries are also exposed to the risk of the epidemic situation, because of their epidemic prevention policies, the epidemic situation can be quickly controlled.

The economy of socialist countries has been damaged to varying degrees in the early stage of the epidemic, but the orderly resumption of work and production after the recovery of the epidemic will pull up the economy again. However, it is undeniable that the unemployment rate has also risen in socialist countries after the epidemic. Unemployment and economic problems can be said to be the common problems of all economies in the world public

\section{CURRENT POLICY}

On 27 July, Trump said on the social platform that he had formally signed the $\$ 2$ trillion and 200 billion economic stimulus bill to tackle the new crown pneumonia epidemic and said it would provide the United States families[15], workers, and enterprises with the most needed assistance. At present, the United States has adopted the "Care" as its economic policy, which issued more than $\$ 500$ billion in unemployment and tax rebate personal insurance. According to reports, Biden said that he is working out trillions of dollars rescue plan, which will increase the economic stimulus funds provided to American individuals to 2000 dollars, expand unemployment insurance, provide billions of dollars of aid to city and state governments, and quickly take action to deal with the deteriorating economic situation and the epidemic situation.

Japan's cabinet meeting decided to launch the third supplementary budget of this fiscal year with the fiscal expenditure of more than 19 trillion yen (about 104 yen per US dollar) to further increase economic stimulus.

The Portuguese government says it plans to invest 2 billion 500 million euros to revive the tourism industry which suffered heavy losses from COVID-19.

At the initial stage, the epidemic has a huge impact on the service consumption industry, leading to the main unemployment in the catering industry, tourism industry, and hotel industry. Therefore, the state should take the lead in investing funds and financial subsidies

\section{CONCLUSION}

According to the current situation, the global epidemic situation is basically in a state of recovery. Based on the above theory and the analysis of the actual situation, the following conclusions are drawn: As an exogenous disaster, the global economic situation is not optimistic. As two important economic indicators, the unemployment rate and CPI fluctuate to a certain extent, which will have a sustained impact on the economic situation in the next few years. It is difficult to recover to the economic and production level before the epidemic.; The current Rescue Behavior of capitalist countries will have an impact on the global economy. Based on the known theory that economic crisis is an insurmountable weakness of capitalism, after the epidemic, excessive economic policies will lead to a new round of economic crisis or financial crisis.; Based on the global layoffs in the epidemic, the unemployment rate will continue to rise after the end of the epidemic and will continue to intensify, mainly in the tourism, service industry, catering industry, education industry, etc.

Based on this situation, suggestions are put forward: China should continue to promote the supply-side structural reform, take the lead in curbing the continued economic downturn, put forward more relaxed monetary and fiscal policies, and vigorously develop the real economy. To defuse the current domestic financial market risks, and lead the world out of trouble. Moreover, Global cooperation, especially in the sphere of public health and economic development, is essential."[16]; The targeted epidemic recovery fund and fiscal stimulus policy in capitalist countries should pay attention to moderation. At present, such fiscal expenditure is greater than fiscal revenue, resulting in a fiscal deficit. Fiscal stimulus will be useful in the short term, however, it might cause inflation in the long term.

\section{ACKNOWLEDGMENT}

First and foremost, I appreciate my senior school which gives me a comfortable learning atmosphere. Second, I would like to show my deepest gratitude to my supervisor, Miss Chen, who has helped me through all the stages of the writing of this thesis. Without her illuminating instruction and patience, this thesis could not have reached its present form. I am also greatly indebted to all my teachers, they have all given me inspirations on knowledge that I used. Last but not least, my sincere appreciation also goes to all my classmates, who were concerned with my writing progress and supporting me to finish this essay.

\section{REFERENCES}

[1] Consumer Price Index USA. (2021) https://fred.stlouisfed.org/series/CPIAUCSL-

[2] Consumer Price Index China (2021) https://tradingeconomics.com/china/consumer-priceindex-cpi

[3] Consumer Price Index European Union https://tradingeconomics.com/european-union/consu mer-price-index-cpi

[4] Unemployment Rate USA. (2021) https://fred.stlouisfed.org/series/UNRATE

[5] Unemployment Rate China (2021)https://www.ceicdata.com/zh-hans/indicator/c hina/unemployment-rate 
[6] Unemployment Rate European Union (2021) https://tradingeconomics.com/european-union/unem ployment-rate

[7] Fernandes, Nuno, Economic Effects of Coronavirus Outbreak (COVID-19) on the World Economy (March 22, 2020). IESE Business School Working Paper No. WP-1240-E, Available at

SSRN: https://ssrn.com/abstract=3557504 or http://d x.doi.org/10.2139/ssrn.3557504

[8] Francis Fukuyama USA. (2021) The decline of neoliberalism and China's anti-epidemic model https://www.huxiu.com/article/351606.html

[9] Unemployment Rate UK. (2020) Britain's unemployment rate in the third quarter http://www.xinhuanet.com/fortune/2020-11/11/c_11 26724985.htm

[10]Unemployment Rate Italy(2021), https://cn.knoema.com/atlas/\%e6\%84\%8f\%e5\%a4\% a7\%e5\%88\%a9/\%e5\%a4\%b1\%e4\%b8\%9a\%e7\%8e $\% 87$

[11] Shibai Liu. On over financialization and the financial crisis in the United States [J]. Economic trends, 2010 (04): 20-27

[12]Feipeng Lou, COVID-19's economic and financial impact and response proposals -- Based on the perspective of infectious diseases $[\mathrm{J}]$. southwest finance, 2020 (04): 34-43.

[13] The gap between the rich and poor USA. (2020)Institute for policy studies

[14] new.qq.com China (2021) The outbreak rebounded after the unsealing, and Cuba re-sealed the capital, Havana https://.qq.com/omn/20200809/20200809A09THX0 $0 . \mathrm{htm}$

[15]Ding Ye China (2021) Trump signs the biggest economic bill https://new.qq.com/omn/20200328/20200328A03U YJ00.html

[16] McKibbin, Warwick J. and Fernando, Roshen, The Global Macroeconomic Impacts of COVID-19: Seven Scenarios (March 2, 2020). CAMA Working Paper No. 19/2020, Available at SSRN: https://ssrn.com/abstract=3547729 or http://d x.doi.org/10.2139/ssrn.3547729 